\title{
O SIGNIFICADO DO TRABALHO PARA OS ARTESÃOS DA REGIÃO DO CARIRI CEARENSE
}

\author{
R. . R. GRANGEIRO ${ }^{1}$, A. V. B. BASTOS ${ }^{2}$ \\ ${ }^{1}$ Universidade Federal do Cariri, ${ }^{2}$ Universidade Federal da Bahia \\ rebeca.grangeiro@ufca.edu.br ${ }^{1}$
}

Submetido 29/08/2017 - Aceito 20/02/2018

DOI: $10.15628 /$ holos.2018.6256

\section{RESUMO}

O objetivo deste artigo é analisar como artesãos significam o trabalho que realizam. Para coleta de dados, utilizamos versão reduzida do instrumento de pesquisa construído pela equipe Meaning of Work International Research Team - MOW - durante os anos 1980, traduzido e validado no Brasil por Soares (1992). Conforme orientação do modelo teórico adotado, o significado do trabalho é analisado a partir de três dimensões: centralidade do trabalho, normas sociais do trabalho e resultados e objetivos valorizados do trabalho. A partir da realização de análises estatísticas descritivas examinamos o comportamento da amostra de artesãos investigados frente às dimensões que integram o modelo de significado do trabalho da equipe
MOW (1987). Adicionalmente, operamos a comparação entre médias de quatro perfis de artesãos, para as dimensões citadas. A média de centralidade absoluta do trabalho para os artesãos é alta e não foi observada diferença relevante entre as médias dos quatro perfis analisados. Quanto à centralidade relativa, o trabalho obteve segunda maior média. Os artesãos do Cariri cearense apresentaram uma adesão levemente superior às normas de direitos quando comparadas às normas de deveres. No exame da dimensão resultados esperados do trabalho, encontramos diferenças entre as médias dos quatro perfis e na ordem dos resultados mais valorizados.

PALAVRAS-CHAVE: Trabalho artesanal, centralidade do trabalho, direitos e deveres do trabalho, resultados esperados do trabalho.

\section{THE MEANING OF WORK FOR THE ARTISANS OF CARIRI - CEARÁ (BRAZIL)}

\begin{abstract}
The purpose of this article is to analyze how craftsmen mean the work they do. For collecting data, we used a reduced version of the survey built by the Meaning of Work International Research Team - MOW - during the $80 \mathrm{~s}$ and translated and validated in Brazil by Soares (1992). According to the theoretical model adopted, the meaning of work is analyzed based on three major dimensions: the centrality of work, the social norms of work, and the valued results of work. Based on the realization of descriptive statistical analysis we examined the behavior of the total sample of craftsmen investigated in relation to the three dimensions that
\end{abstract}

integrate the MOW's model of meaning work. In addition, we compared the means of four artisans' profiles, for the dimensions cited. The mean of centrality work is high and it was not observed significant difference between the mean of the four analyzed profiles. The artisans of Cariri/Ceará showed a slightly higher adherence to rights-oriented social norms than the duties-oriented social norms. In the examination of the expected results, we found differences between the averages of the four profiles and differences in the order of the most valuable results.

KEYWORDS: Artisan work, centrality of labor, rights and duties of the job, expected results of the work. 


\section{APRESENTAÇÃO}

Observamos historicamente diversas maneiras de perceber o trabalho, ora como um fardo, ora como atividade fundamental e estruturante do ser humano. Diferentes contextos sociais e culturais também influenciam o modo como os indivíduos atribuem significado ao trabalho que realizam. Atentos às mudanças históricas e às peculiaridades sociais e culturais da região do Cariri cearense, buscamos analisar como os artesãos desta localidade atribuem significado ao trabalho que realizam.

A região do Cariri cearense possui uma produção artesanal que se destaca nos cenários regional e nacional pela variedade de objetos, de tipologias e por resgatar elementos da cultura local (interiorana, sertaneja). Identificamos na região um grupo de profissionais que conferem tal visibilidade ao artesanato caririense. Eles são habilidosos tecnicamente, comercializam sua produção no mercado interno e exportam, dedicam-se apenas ao artesanato como atividade produtiva, da qual obtém renda suficiente para se manter. No entanto, detectamos também artesãos com características que indicam uma situação de fragilidade ocupacional. Estes não conseguem escoar a produção para além das fronteiras da cidade onde habitam e possuem o artesanato como atividade produtiva secundária, realizada para complementar a renda familiar.

A fim de apontar e compreender diferenças e aproximações na maneira como estes profissionais lidam com o artesanato, Grangeiro (2015) observa o trabalho artesanal a partir de três etapas (acesso e tratamento da matéria-prima; produção; e comercialização), examinando possíveis mudanças na forma como ela ocorre ao longo da carreira do artesão (inovação) e o alcance geográfico dos objetos produzidos (visibilidade). Ao se relacionar o nível de inovação nos processos de trabalho com o nível de visibilidade alcançado pelos objetos produzidos, a autora propõe um modelo de análise da atividade artesanal que classifica artesãos em quatro perfis.

O primeiro perfil inclui artesãos tradicionais reconhecidos, são aqueles que apresentaram baixas médias em inovação e altas em visibilidade, refere-se a um grupo de artesãos que produzem artesanato tradicional, a partir de matéria-prima típica da localidade onde vive, utilizando técnicas de trabalho tradicionais. Pouca ou nenhuma inovação ocorre em relação ao processo de produção, já a inovação em relação ao artefato se limita a atualizações estimuladas por mudanças no contexto social, cultural e político em que vive o artesão (Grangeiro \& Bastos, 2016).

O segundo apresenta ao mesmo tempo baixos índices em inovação e visibilidade. Os artesãos deste grupo são denominados artesãos tradicionais não-reconhecidos. Eles não inovaram no que diz respeito ao artefato criado, às técnicas de produção utilizadas, à forma de comercialização. Estes artesãos tampouco conseguiram aprimorar estilo próprio que os distinguisse dos demais artesãos de sua tipologia. Na maioria das vezes, repetem mecanicamente as técnicas do fazer artesanal, utilizam matéria-prima nativa da região do Cariri cearense, no entanto, produzem os mesmos artefatos que produziam antes da ascensão industrial na região, quando tinham amplo mercado de consumo (Grangeiro \& Bastos, 2016).

O terceiro perfil é composto por artesãos com média baixa em visibilidade e alta em inovação, são denominados artesãos de referência cultural não-reconhecidos. Neste grupo, os artefatos criados não ultrapassam o limite geográfico estadual de visibilidade, no entanto 
observamos inovação em alguma (s) das três etapas do fazer artesanal (Grangeiro \& Bastos, 2016).

Finalmente, o quarto perfil representa os artesãos com altas médias de inovação e visibilidade e são denominados de referência cultural reconhecidos. O alto grau de inovação, característico deste perfil, refere-se não somente à inovação no produto criado, mas também à inovação no processo produtivo, que podem se referir ao emprego de novas técnicas, e também a mudanças no preparo da matéria-prima, por exemplo, o uso de técnicas para colorir o couro ou a palha. Além das inovações no produto, assessoradas pelo contato com o design ou arte, a maestria no ofício, a qualidade e a beleza estética do artesanato produzido geram alto padrão de visibilidade do mesmo. Os artesãos e artesãs representados (as) neste quadrante superam o alcance geográfico local e ganham visibilidade nacional e internacional (Grangeiro \& Bastos, 2016).

Observando a classificação delineada acima, propomos como objetivo geral deste artigo analisar diferenças e semelhanças na forma como artesãos integrantes de quatro perfis artesanais (tradicional reconhecido, tradicional não-reconhecido, de referência cultural nãoreconhecido e de referência cultural reconhecido) atribuem significado ao trabalho artesanal. 0 modelo teórico elaborado pela equipe Meaning of Work International Research Team (MOW, 1987) fundamentou a coleta de dados sobre o significado do trabalho junto aos artesãos, bem como as dimensões teóricas que compõem o modelo de análise dos dados.

A escolha por nos fundamentar no trabalho realizado pela equipe MOW (1987) deve-se ao fato de ele ser considerado um estudo clássico no tema e por ter se mostrado eficiente em demonstrar diferenças culturais entre amostras. Tais características nos parecem pertinentes no exame do significado do trabalho para artesãos, uma vez que possuímos uma amostra de trabalhadores que possuem peculiaridades sociais e culturais, a saber: baixa escolaridade, renda inferior a um salário mínimo, não se situar em grandes centros urbanos e forte apelo religioso da localidade. Tais particularidades se sobressaem quando artesãos são comparados aos grupos de trabalhadores tradicionalmente estudados no domínio da Psicologia Organizacional e do Trabalho - POT.

Assim, de modo específico pretendemos: 1) caracterizar a centralidade do trabalho para artesãos dos quatro perfis delineados; 2) examinar possíveis diferenças e semelhanças destes quatro grupos em perceber o trabalho, atribuindo maior peso à sua concepção como um direito do cidadão ou como um dever perante a sociedade; 3 ) analisar os resultados do trabalho mais valorizados por artesãos tradicionais reconhecidos, tradicionais não-reconhecidos, de referência cultural não-reconhecidos e de referência cultural reconhecidos.

A fim de cumprir os objetivos apresentados, o presente artigo possui quatro seções, nas quais abordamos consecutivamente o modelo teórico sobre significado do trabalho que fundamenta o estudo; a descrição do método utilizado; a apresentação e discussão dos resultados encontrados e, por último, as considerações finais.

\section{SIGNIFICADO DO TRABALHO: ALGUMAS CONSIDERAÇÕES PRELIMINARES}

O estudo do significado do trabalho começou a ocorrer de forma sistemática, em psicologia, a partir da década de 1980 (Borges \& Yamamoto, 2010; Borges \& Barros, 2015; 
Bendassolli \& Borges-Andrade, 2015b). Neste processo, o esforço de pesquisa realizado pelo grupo MOW (1987) se destaca como um dos estudos pioneiros sobre o tema, além de ter influenciado o crescimento da quantidade de pesquisas ao redor do mundo e, sobretudo no Brasil (Soares, 1992; Bastos, Pinho e Costa, 1995; Borges, 1997; 1999).

As pesquisas realizadas pela equipe MOW (1987) são, sem dúvida, impulsionadoras de novas investigações sobre o significado do trabalho (Borges \& Yamamoto, 2010), que nos dias atuais, é também considerado um estudo clássico sobre o tema. Borges, Tamayo e Alves-Filho (2005) e Borges e Yamamoto (2010) apontam quatro razões principais que justificam a importância desta pesquisa para o estudo do tema: 1) popularização da noção de centralidade do trabalho; 2) identificação de elevada centralidade do trabalho em diversos países, ao contrário das previsões realizadas; 3) incorporação da noção de normas sociais como componente do construto; 4) consideração do caráter sistêmico do significado do trabalho.

Os estudos sobre significado do trabalho apresentam distinções quanto às dimensões que compõem o construto. A centralidade do trabalho é a dimensão consensualmente abordada por diferentes modelos teóricos de significado do trabalho. Porém, diferente do modelo elaborado pela equipe MOW (1987), os modelos construídos por Borges e Tamayo (2001) e Borges e Yamamoto (2010), propõem, além da centralidade, os atributos valorativos (justiça; realização pessoal; sobrevivência; desgaste) e descritivos (auto expressão; independência e recompensa econômica; responsabilidade; condições de trabalho) como dimensões do significado do trabalho. Por sua vez, Bendassolli e Borges-Andrade (2011) avaliam as dimensões de função social do trabalho, ética, autonomia, qualidade nas relações, expressividade e identificação no trabalho, no exame do significado do trabalho para trabalhadores inseridos na indústria criativa, os dados psicométricos de tal escala são detalhados em Bendassolli e Borges-Andrade (2015b).

Analisando as literaturas nacional e internacional sobre o tema, Bendassolli e BorgesAndrade (2015a) delimitam seis grandes tópicos de pesquisa sobre significado do trabalho, que se inspiram na definição tema como representações e mapas cognitivos que organizam a experiência do indivíduo com o trabalho. Os principais objetivos de cada linha de pesquisa, bem como alguns pesquisadores que a representam são abordados na tabela 1. 
Tabela 1. Grandes tópicos de pesquisa sobre significado do trabalho e principais estudos.

\begin{tabular}{|c|c|c|}
\hline \multicolumn{2}{|c|}{ Tópicos de pesquisa } & \multirow{2}{*}{$\begin{array}{l}\text { Pesquisadores } \\
\text { Dubin (1956); Gonzales e Vilela (2005); Harpaz e Fu } \\
\text { (1997); Kanungo (1982); MOW (1987); Salanova, } \\
\text { Garcia e Peiró (1996); Tomás (1998) }\end{array}$} \\
\hline 1 & $\begin{array}{l}\text { Refere-se ao envolvimento com o trabalho e à } \\
\text { centralidade do trabalho, buscando determinar a } \\
\text { importância do trabalho, quando comparada a outras } \\
\text { esferas da vida. }\end{array}$ & \\
\hline 2 & $\begin{array}{l}\text { Inclui pesquisas que investigam o tipo de orientação } \\
\text { (instrumental ou expressiva) que as pessoas têm frente a } \\
\text { seu trabalho, se o encaram como emprego, carreira ou } \\
\text { vocação. }\end{array}$ & $\begin{array}{l}\text { Kaplan e Tausky (1974); MOW (1987); } \\
\text { Wrzesniewski, McCauley, Rozin e Schwartz (1987) }\end{array}$ \\
\hline \multicolumn{2}{|r|}{$\begin{array}{l}\text { Aborda pesquisas que buscam identificar os objetivos que os } \\
\text { indivíduos procuram alcançar através do trabalho que realizam } \\
\text { e em examinar as representações cognitivas ou os padrões de } \\
\text { significado que estão associados com o trabalho, por exemplo, } \\
\text { o trabalho como fonte de prazer, uma obrigação ou um } \\
\text { direito. }\end{array}$} & $\begin{array}{l}\text { Borges (1997); Buchholz (1977); Ros, Schwartz e } \\
\text { Surkiss (1999); Super e Sverko (1995) }\end{array}$ \\
\hline \multicolumn{2}{|r|}{$\begin{array}{l}\text { Abrange estudos sobre causas e consequências da ausência } \\
\text { prolongada de trabalho, incluindo a análise de estratégias de } \\
\text { enfrentamento. }\end{array}$} & Brief e Nord (1990); Feather (1990); Warr (1987) \\
\hline 3 & $\begin{array}{l}\text { Refere-se à compreensão de por que o trabalho possui } \\
\text { tantos significados diferentes para pessoas diferentes. As } \\
\text { pesquisas que se enquadram neste tópico buscam } \\
\text { identificar padrões de significado e contextualizá-los. }\end{array}$ & $\begin{array}{l}\text { Allend, Saez, Apodaka, Castañares e Ardanaz } \\
\text { (2003); Dakduk, González e Montilla (2008); } \\
\text { Drenth (1991); England e Harpaz (1990); Gómez } \\
\text { (2004); Garcia, Martín, Rodriguez e Peiró (2001); } \\
\text { Martínez, Soria, Cifre e Gumabu (2001); MOW } \\
\text { (1987) }\end{array}$ \\
\hline \multicolumn{2}{|r|}{$\begin{array}{l}\text { Inclui estudos sistemáticos sobre representações sociais do } \\
\text { trabalho. }\end{array}$} & $\begin{array}{l}\text { Borges (1996); Moliner, Rateau e Cohen-Scali } \\
\text { (2002); Suárez, Torregrosa, Bergère e Alvaro } \\
(1998)\end{array}$ \\
\hline
\end{tabular}

Fonte: Bendassolli e Borges-Andrade (2015a)

A pesquisa realizada pelo grupo MOW (1987) aparece em três dos grandes tópicos acima citados. Eles estão destacados no quadro, a partir dos números 1, 2 e 3 . Além de vanguardista no tocante aos estudos sobre significado do trabalho, influenciou inúmeras outras pesquisas sobre $o$ tema e é, atualmente, considerado um estudo clássico na área.

Conforme apontado por Grangeiro e Bastos (2016), os artesãos do Cariri cearense apresentam características e peculiaridades sociais e culturais que os distingue dos trabalhadores industriais urbanos. Por isso, optamos por um modelo de análise hábil em capturar estas diferenças. Outrossim, exposta a relevância do trabalho da equipe MOW para os estudos brasileiros, acreditamos estar justificada a escolha de adotar o modelo teórico elaborado pela equipe MOW (1987) para pautar nossa investigação (da coleta à análise dos dados) sobre significado do trabalho para trabalhadores artesãos da região do Cariri cearense.

2.1 Conceituação das dimensões propostas pela equipe MOW: centralidade, normas sociais e resultados do trabalho

A estrutura conceitual sobre significado do trabalho proposta pela equipe MOW (1987) envolve três grandes dimensões: centralidade do trabalho, normas sociais do trabalho, e resultados e objetivos valorizados do trabalho. Cada uma destas dimensões será brevemente descrita a seguir. 
A centralidade do trabalho representa uma medida geral da importância do trabalho, em determinado momento da vida dos indivíduos. MOW (1987, p. 17) também apresenta a centralidade do trabalho como "conviç̧ão geral acerca do valor do trabalho na vida de um indivíduo". A centralidade do trabalho possui dois componentes teóricos: o primeiro constitui uma avaliação absoluta, ou global da importância do trabalho para a vida do indivíduo, e o segundo está orientado para decisão sobre qual ou quais esferas da vida são preferidas (Tolfo, 2015). As pessoas tendem a participar mais da esfera da vida de sua preferência e menos de esferas não tão preferidas e desta forma podemos perceber a posição ocupada pelo trabalho, quando sua importância é analisada conjuntamente com a importância aferida à família, lazer, religião e comunidade.

A centralidade do trabalho é considerada um "conceito consagrado" nos estudos sobre significado do trabalho (Borges \& Yamamoto, 2010; Bendassolli, 2009), pois é um elemento comum aos diversos modelos teóricos de significado do trabalho e não somente ao modelo proposto pela equipe MOW (1987).

As normas sociais do trabalho são crenças e expectativas normativas dos indivíduos sobre seus direitos e deveres no trabalho. As normas orientadas para os direitos se referem às responsabilidades da sociedade e das organizações de oferecerem aos indivíduos um trabalho significativo e interessante; o direito de participar nas decisões sobre a forma de executar o trabalho, além de decidir sobre outros aspectos relativos ao trabalho. As normas orientadas para os deveres, por sua vez, referem-se às obrigações individuais e coletivas que as pessoas possuem para com a sociedade, na situação de trabalho. No escopo dos deveres estão às obrigações de garantir o próprio futuro, de refletir sobre a melhor forma de realizar o próprio trabalho e de valorizar o trabalho que realiza independente da sua natureza, desde que o salário compense (Bastos, Pinho \& Costa, 1995).

As normas sociais têm sofrido influência das mudanças ocorridas no mundo do trabalho ao longo dos anos. Avanços tecnológicos, atualização de modelos administrativos gerenciais, ampliação da participação feminina no mercado de trabalho, da escolarização formal, desenvolvimento do setor de serviços em diversos países são fatores que impactam nos tipos e na quantidade de empregos, bem como nas normas que orientam direitos e deveres acerca do trabalho (Kubo, Gouvêa \& Mantovani, 2009).

O estudo do significado do trabalho não está completo se não envolver o exame dos resultados e objetivos valorizados no trabalho. Trata-se de um conceito que se relaciona com as finalidades que as atividades de trabalho possuem para o indivíduo, ou seja, é uma resposta à indagação acerca do por que o indivíduo trabalha, o que o motiva a trabalhar. Estas motivações, conforme o modelo da equipe MOW (1987), referem-se: 1 ) ao status ou prestígio social adquirido a partir da atividade realizada; 2) à função econômica do trabalho; 3) manter-se ocupado, em atividade; 4) estabelecer contatos sociais; 5) sentir-se realizando algo de útil para a sociedade; e 6) sentir-se auto realizado com as tarefas e/ou papel que realiza. Esta dimensão ressalta o caráter motivacional do significado do trabalho, que se concretiza através das metas que o indivíduo estabelece e busca alcançar através do seu trabalho e da valorização atribuída aos resultados. $\mathrm{Na}$ tabela 2, as três dimensões de significado do trabalho são abordadas de forma sintética. 
Tabela 2. Dimensões do significado do trabalho segundo equipe MOW (1987)

\begin{tabular}{l|l}
\hline Dimensões & Conceitos \\
\hline Centralidade do trabalho & $\begin{array}{l}\text { O grau de importância atribuída ao trabalho frente às demais esferas da } \\
\text { vida (família, religião, lazer e comunidade). }\end{array}$ \\
\hline Normas sociais & $\begin{array}{l}\text { Referem-se às características do trabalho que exprimem o balanço das } \\
\text { obrigações individuais para a sociedade e vice-versa. }\end{array}$ \\
\hline Resultados e objetivos valorados & $\begin{array}{l}\text { São as metas que os indivíduos esperam alcançar por intermédio do seu } \\
\text { trabalho e na valorização atribuída aos resultados esperados. }\end{array}$ \\
\hline
\end{tabular}

Fonte: Borges e Yamamoto (2010)

Neste modelo, o significado do trabalho é influenciado pelos contextos organizacional, familiar e social que o indivíduo vivencia, ou seja, as experiências familiares, sociais e de trabalho impactam na forma como cada um atribui significado ao trabalho. Desta forma, temos um modelo que concebe o significado do trabalho como um construto psicológico multidimensional e dinâmico, formado pela interação de variáveis pessoais e ambientais (Bendassolli, Alves \& Torres, 2014).

\section{MÉTODO}

\subsection{Instrumento}

O instrumento que utilizamos para avaliar como os artesãos atribuem significado ao trabalho que realizam fundamenta-se no instrumento utilizado pela equipe MOW (1987). Utilizamos uma versão reduzida desta medida, traduzida e validada para realidade brasileira por Soares (1992), que contempla as três dimensões previstas no modelo teórico: centralidade do trabalho, normas sociais relativas ao trabalho e resultados esperados.

Em relação à centralidade do trabalho, ela foi mensurada em sua forma absoluta, onde o artesão responde se a atividade artesanal é uma atividade de grande, média ou pouca importância na sua vida, a partir de uma escala tipo Likert de sete pontos. Também foi avaliada a centralidade relativa do trabalho, na qual a importância do trabalho é comparada à importância de outras esferas da vida do indivíduo, a saber: família, religião, lazer e comunidade. Para tal, os participantes foram convidados a distribuir um total de 100 pontos entre as cinco esferas, sabendo que às esferas mais importantes eles deveriam atribuir maior pontuação e àquelas de menor importância, deveriam conferir menor pontuação.

No instrumento de pesquisa utilizado, também foram avaliadas as normas sociais do trabalho, que dizem respeito aos direitos e deveres relativos ao trabalho. A questão é composta por oito itens, dos quais quatro são relativos às normas sociais orientadas para as obrigações e deveres do trabalhador e outros quatro abordam os direitos do trabalhador. Os itens que compõem direitos se referem às responsabilidades das organizações e da sociedade sobre todas as pessoas, no sentido que todos teriam direito a um trabalho significativo e interessante, a um treinamento adequado para iniciar o exercício da função e para dar continuidade, com qualidade ao serviço; o direito de participar nas decisões sobre métodos de trabalho e outros detalhes relacionados ao trabalho.

Por sua vez, os itens que compõem deveres se referem às obrigações de todos os indivíduos para com a sociedade referentes ao trabalho, e incluem a obrigação de todos trabalharem em prol da sociedade, obrigação de todos em garantir seu futuro e valorizar o 
trabalho de cada um, qualquer que seja a sua natureza. Os respondentes foram convidados a informar em que grau concordavam com as afirmações que lhes foram apresentadas, relativas a direitos e deveres do trabalhador, a partir de uma escala tipo Likert de sete pontos.

A dimensão relativa às funções ou resultados valorizados do trabalho é avaliada a partir da distribuição de 100 pontos entre sete variáveis que dizem respeito a grandes funções do trabalho, são elas: status e prestígio; renda obtida com o trabalho; ocupação do tempo; contato interpessoal; serviço social do trabalho; intrínseca ou auto expressiva; autorrealização. Os 100 pontos deveriam ser distribuídos entre as sete funções, de forma que aquelas que o participante atribuísse maior pontuação para as funções mais relevantes para ele. A análise da maneira como o artesão distribuiu os 100 pontos entre as funções revelam os principais motivos que o levam a trabalhar.

\subsection{Participantes}

O Cariri cearense foi escolhido como espaço para a investigação de campo pois a região constitui o maior polo de artesanato cearense em quantidade e diversidade, além de possuir forte representatividade para a cultura popular do estado do Ceará e do Brasil. Tal diversidade se revela na aglutinação dos tipos mais característicos do artesanato tradicional, onde encontramos santeiros que criam a partir do barro ou madeira, xilogravuristas, seleiros, que além dos artefatos típicos do vaqueiro, ousam na produção de peças direcionadas a um nicho de mercado feminino, ourives e ainda artesãos e artesãs da palha que a partir da criação de peças estilizadas, ressignificam a cultura de homens e mulheres do sertão do Nordeste brasileiro. A localização geográfica do território investigado pode ser visualizada na Figura 3.

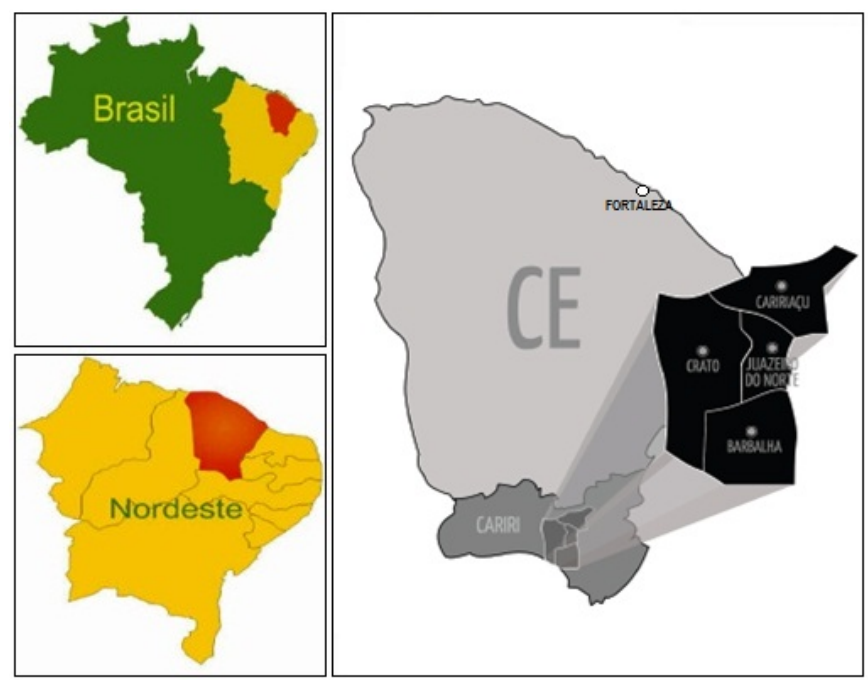

Figura 3. Localização de Juazeiro do Norte no espaço geográfico brasileiro, nordestino, cearense e caririense Fonte: Adaptado de Araújo (2006); Vale e Silva Jr (2012).

A amostra investigada compreende 205 artesãos identificados através de listagem de artesãos fornecida pelo Centro de Artesanato do Ceará (Ceart), associações de artesãos, pontos comerciais de artesanato e contato estabelecido com a Secretaria de Cultura dos oito municípios do Cariri cearense investigados. 
A amostra foi classificada em quatro diferentes perfis, em função dos níveis de inovação e visibilidade alcançados. O primeiro perfil é composto por 38 artesãos que apresentam média baixa em inovação e alta em visibilidade, estes artesãos são denominados tradicionais reconhecidos. O segundo perfil possui 105 artesãos, que apresentam médias baixas em inovação e em visibilidade, eles se chamam artesãos tradicionais não-reconhecidos. São 38 os artesãos do terceiro perfil. Eles apresentam média alta em inovação e baixa em visibilidade e são denominados de referência cultural não-reconhecidos. Por fim, o quarto perfil possui 24 artesãos com médias altas em inovação e em visibilidade e se chamam artesãos de referência cultural reconhecidos. Na Tabela 3, o primeiro perfil será denominado cluster 1, o segundo cluster 2 e assim por diante. A designação cluster se refere à análise estatística realizada.

Tabela 3. Caracterização da amostra quanto aos dados demográficos

\begin{tabular}{|c|c|c|c|c|c|}
\hline & Cluster 1 & Cluster 2 & Cluster 3 & Cluster 4 & Total \\
\hline \multicolumn{6}{|l|}{ Sexo } \\
\hline Masculino & 21 & 20 & 11 & 13 & 65 \\
\hline Feminino & 17 & 85 & 27 & 11 & 148 \\
\hline \multicolumn{6}{|l|}{$X^{2}=27,394 p=0,000$} \\
\hline \multicolumn{6}{|l|}{ Cidade em que reside } \\
\hline Juazeiro do Norte & 15 & 50 & 19 & 16 & 100 \\
\hline Crato & 16 & 30 & 5 & 01 & 52 \\
\hline Barbalha & 00 & 08 & 7 & 02 & 17 \\
\hline Santana do Cariri & 01 & 11 & 2 & 00 & 14 \\
\hline Várzea Alegre & 05 & 00 & 3 & 03 & 11 \\
\hline Caririaçu & 01 & 02 & 0 & 02 & 05 \\
\hline Nova Olinda & 00 & 02 & 2 & 00 & 04 \\
\hline Missão Velha & 00 & 02 & 0 & 00 & 02 \\
\hline \multicolumn{6}{|l|}{$X^{2}=49,695 p=0,002$} \\
\hline \multicolumn{6}{|l|}{ Escolaridade } \\
\hline Não sabe ler, nem escrever & 01 & 07 & 00 & 01 & 09 \\
\hline Alfabetizado & 02 & 05 & 00 & 01 & 08 \\
\hline Ensino fundamental incompleto & 08 & 36 & 04 & 09 & 57 \\
\hline Ensino fundamental completo & 04 & 10 & 03 & 02 & 19 \\
\hline Ensino médio incompleto & 07 & 08 & 05 & 02 & 22 \\
\hline Ensino médio completo & 12 & 29 & 13 & 07 & 61 \\
\hline Ensino superior incompleto & 00 & 05 & 06 & 01 & 12 \\
\hline $\begin{array}{l}\text { Ensino superior completo } \\
X^{2}=40,683 p=0,006\end{array}$ & 04 & 05 & 07 & 01 & 17 \\
\hline \multicolumn{6}{|l|}{ Renda mensal com artesanato } \\
\hline Menos de um salário mínimo & 14 & 79 & 09 & 01 & 103 \\
\hline $1 \mathrm{SM}$ & 10 & 05 & 05 & 04 & 24 \\
\hline$>1$ e 2 SM & 08 & 18 & 20 & 11 & 57 \\
\hline$>2$ e $5 \mathrm{SM}$ & 06 & 03 & 04 & 06 & 19 \\
\hline$>5$ e $10 \mathrm{SM}$ & 00 & 00 & 00 & 02 & 02 \\
\hline$X^{2}=104,863 p=0,00$ & & & & & \\
\hline
\end{tabular}

Fonte: Dados da pesquisa. 
A Tabela 3 apresenta dados da amostra geral e dos quatro subgrupos delimitados, referentes a gênero, cidade de atuação destes profissionais, escolaridade e renda mensal adquirida com artesanato. A maior parte da nossa amostra é constituída por artesãs do sexo feminino ( $N=148$ ), compondo $68,3 \%$ contra $31,7 \%$ de artesãos do sexo masculino $(N=65)$. Os artesãos se distribuem de maneira relativamente uniforme entre os clusters, porém as artesãs se concentram principalmente no segundo cluster. Quanto à escolaridade, observamos que os participantes apresentam baixos níveis de escolaridade, sobretudo se comparamos com os estudos realizados entre trabalhadores urbanos (Rodrigues \& Bastos, 2012; Aguiar, 2016). A partir de um exame da amostra geral, percebemos que aproximadamente $36,1 \%$ dos participantes não concluíram o Ensino Fundamental.

A respeito do município onde o artesão vive e trabalha, identificamos que $82,5 \%$ da amostra total se concentram nas três principais cidades da região: Juazeiro do Norte, Crato e Barbalha, que são as cidades mais populosas e onde se concentram maior quantidade de artesãos. Quanto à renda adquirida com o artesanato, nota-se na Tabela 1 que apenas artesãos com altos níveis de inovação e visibilidade recebem mais de cinco salários mínimos com a atividade artesanal. Enquanto, a maioria dos artesãos que obtém menos de um salário mínimo com o artesanato $(76,7 \%)$ encontra-se no segundo cluster (baixa inovação e visibilidade).

A idade da amostra dos artesãos pesquisados varia entre 10 e 87 anos, sendo a idade média de 42,54 anos, com um desvio padrão de 15,46 anos. A Tabela 4 apresenta a comparação das médias de idade, tempo de trabalho com artesanato e horas diárias trabalhadas entre artesãos dos quatro perfis analisados e da amostra total.

Tabela 4. Caracterização da amostra quanto a idade, tempo de profissão e horas trabalhadas por dia

\begin{tabular}{llllllll}
\hline & Cluster 1 & Cluster 2 & Cluster 3 & Cluster 4 & Total & F & p \\
\hline Idade & $37,7(14,8)$ & $43,4(16,8)$ & $42,7(16,8)$ & $42,5(15,4)$ & $42,5(15,4)$ & 1,9 &, 1 \\
Tempo de trabalho & $15,5(1,5)$ & $22,7(16,5)$ & $22,3(12,9)$ & $30,1(13,8)$ & $22,2(15,7)$ & 4,8 &, 00 \\
Horas/dia & $8,1(2,1)$ & $6(2,8)$ & $6,4(3,4)$ & $8,5(3)$ & $6,7(2,9)$ & 9,3 &, 00 \\
\hline
\end{tabular}

Fonte: Dados da pesquisa.

Observamos que o grupo mais jovem de artesãos e com menos tempo de profissão integram o primeiro cluster, enquanto o quarto cluster compreende os artesãos com maior média de tempo de profissão. Quanto à média de horas diárias trabalhadas, identificamos que os artesãos dos clusters 2 e 3 apresentam as menores médias diárias de horas trabalhadas (respectivamente 6 e 6,4 horas/dia). Por sua vez, os artesãos dos clusters 1 e 4 possuem média de horas trabalhadas por dia superior a oito, portanto maiores que as médias observadas nos cluster 2 e 3.

\subsection{Procedimentos de coleta e análise dos dados}

Quanto ao procedimento de coleta de dados, podemos informar que a mesma se deu por meio de entrevista guiada por questionário (Rogelberg, Church, Waclawski, Stanton, 2004). Optamos por este procedimento devido ao baixo nível de escolaridade da amostra pesquisada, que impossibilitou a aplicação clássica de questionário. Utilizamos escalas coloridas, a fim de facilitar a compreensão dos níveis de concordância da escala Likert, conforme sugestão de Borges 
e Pinheiro (2002) de adaptação dos instrumentos de pesquisa para amostras de baixa escolaridade.

A aplicação do questionário de significado do trabalho junto aos artesãos do Cariri cearense nos forneceu dados numéricos, que passaram por tratamentos estatísticos, conforme as características das variáveis analisadas. Para a tabulação e análise destes dados, foi utilizado o software estatístico SPSS (Statistical Package for Social Sciences). A fim de caracterizar a amostra investigada quanto às dimensões do significado do trabalho foram realizadas análises estatísticas descritivas, tais como média, moda, mediana, bem como medidas de dispersão. Para estabelecermos comparações entre as médias dos quatro segmentos da amostra investigada realizamos a análise de variância (ANOVA) e apresentamos os valores da razão $F$ e da significância p.

\section{RESULTADOS E DISCUSSÃO}

Os resultados apresentados nesta seção se encontram estruturados entre as três dimensões que definem o construto do significado do trabalho, conforme modelo teórico proposto pela equipe MOW (1987) e que, por sua vez, compreendem os objetivos específicos delineados neste artigo: centralidade absoluta e relativa do trabalho; normas societais e resultados valorizados ou esperados.

Considerando toda a amostra investigada, a média da importância global do trabalho na vida foi 6,46 ( $D P=0,888)$. Quando comparamos os quatro grupos de artesãos que se diferenciam quanto aos níveis de inovação e visibilidade alcançados não identificamos diferença entre a média dos quatro grupos, uma vez que o cluster 1 obteve média de 6,45 ( $D P=0,8)$, o cluster 2 obteve média de $6,49(\mathrm{DP}=0,8)$, o cluster 3 obteve média de $6,33(\mathrm{DP}=0,9)$ e o cluster 4 obteve média de $6,45(\mathrm{DP}=0,87)$, com $F(199)=0,262, \mathrm{p}>0,05$. Ainda vale destacar a elevada importância atribuída ao trabalho pelos participantes, que é ratificada pelos escores que se aproximam à pontuação máxima prevista pela escala utilizada.

A centralidade relativa do trabalho é avaliada a partir da média de importância do trabalho em relação a outras esferas da vida: lazer, comunidade, religião e família. Analisando a amostra em sua totalidade, identificamos que a família constitui a esfera mais central, seguida do trabalho. Assim, os dados relativos à ordem de importância atribuída a estas duas esferas pelo grupo de trabalhadores artesãos estão em consonância com os achados das pesquisas conduzidas pelo grupo MOW (1987) em diversos países e também com os resultados encontrados por pesquisas brasileiras sobre o significado do trabalho (Soares, 1992; Bastos, Pinho \& Costa, 1995; Borges \& Tamayo, 2001; Borges \& Yamamoto, 2010; Bendassolli, Alves \& Torres, 2014; Bastos \& Aguiar, 2015).

Observamos que para a amostra em questão, a religião aparece em terceiro lugar de importância com média consideravelmente superior às esferas comunidade e lazer. Dentre os estudos científicos acima citados, só encontramos resultado semelhante em Bastos e Aguiar (2015) que também examinaram amostra de trabalhadores rurais e de baixa escolaridade. 0 resultado encontrado ainda pode ser atribuído a alta religiosidade, característica marcante da comunidade local (Araújo, 2014). As médias das cinco esferas da vida analisadas na centralidade relativa do trabalho estão representadas na figura 2. 
¿azer $\square$ Comunidade $\square$ Trabalho $\square$ Religião $\square$ Família

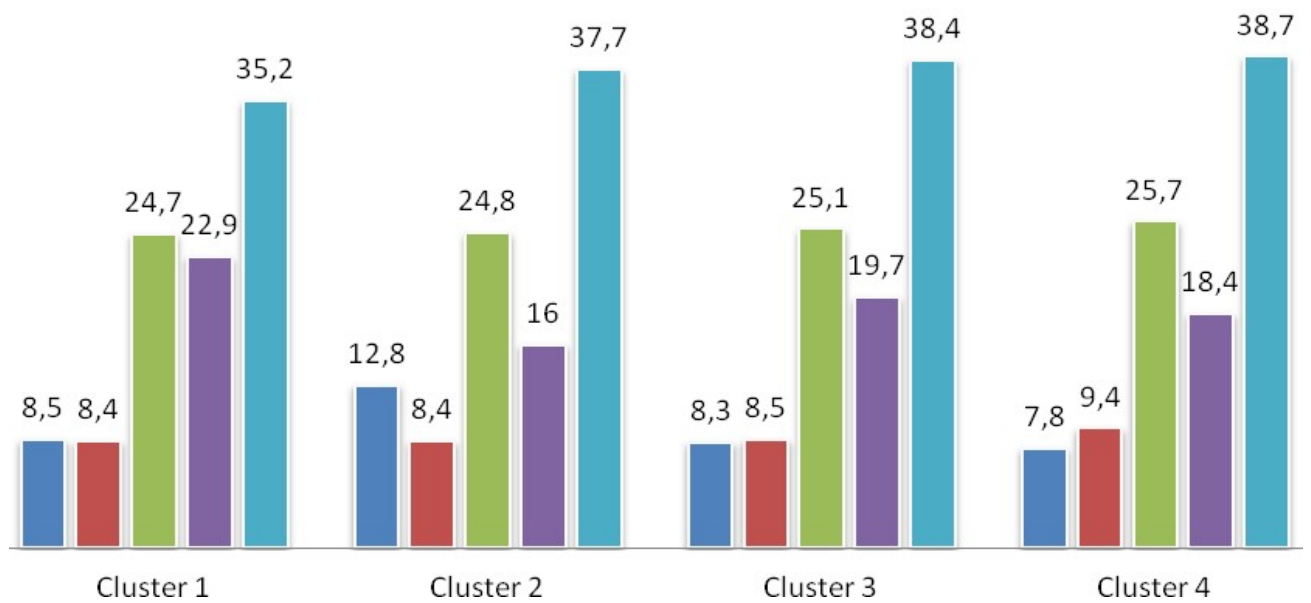

Figura 2. Comparação de médias de centralidade do trabalho para os quatro perfis artesanais investigados. Fonte: Dados da pesquisa.

Destacando a comparação entre as médias obtidas nas esferas trabalho e lazer, identificamos que artesãos com altos escores de inovação e visibilidade (cluster 4) apresentam maiores médias em trabalho que artesãos de baixas inovação e visibilidade (cluster 2), a estatística $F(199)=0,4$ e $p=0,9^{1}$. Por sua vez, no que diz respeito à esfera lazer, observamos o inverso, ou seja, os artesãos de baixa inovação e visibilidade (cluster 2) apresentaram média nesta esfera da vida, superior à média obtida pelos artesãos de alta inovação e visibilidade (cluster 4), com $F(199)=2,9$ e $p=0,03$.

Tais dados parecem fazer mais sentido, quando comparamos a média de horas diárias trabalhados por estes dois grupos. Os artesãos do cluster 4 (denominados artesãos de referência cultura reconhecidos) se dedicam em média 2,5 horas diárias a mais ao trabalho artesanal que os artesãos do cluster 2 (denominados artesãos tradicionais não reconhecidos). Apresentando $\mathrm{F}$ $(229)=9,318 ; p<0,01$, o que pode indicar a maior importância que o grupo de artesãos de alta visibilidade atribui ao trabalho e que, ao mesmo tempo, limita suas horas disponibilizadas ao lazer.

Sobre a centralidade do trabalho, podemos dizer sinteticamente que as quatro porções da amostra de artesãos analisadas (que variam quanto ao nível de inovação observado nos processos de trabalho e de visibilidade alcançado pelo objeto artesanal) se comportam de maneira bastante semelhante, quando avaliamos o trabalho isoladamente. No entanto, quando convocados a comparar o trabalho com outras áreas da vida, observamos diferenças entre as médias dos quatro grupos de artesãos nas esferas de trabalho, família, religião e lazer.

As normas sociais do trabalho foram avaliadas em relação aos direitos e deveres relativos ao trabalho. Inicialmente, sem estabelecer comparações entre segmentos da amostra

\footnotetext{
${ }^{1}$ Apesar de os valores de $\mathrm{p}$ serem superiores a 0,05, o que indica que as diferenças entre as médias não são significativas (podem ter se dado ao acaso), optamos por, ainda assim, destacar as diferenças entre as médias dos quatro segmentos da amostra, pois compreendemos que o nível de significância é um dado estatístico fortemente influenciado pelo tamanho da amostra e seu valor acima do admitido estatisticamente pode ser um reflexo do número relativamente baixo de artesãos em cada um dos grupos analisados.
} 
investigada, examinamos a média da norma relativa a deveres de 5,84 $(D P=0,95)$ e a média da norma relativa a direitos de 6,37 ( $D P=0,72)$. Desta forma, identificamos que os artesãos do Cariri cearense apresentaram uma adesão levemente superior às normas de direitos do que às normas de deveres.

Tabela 5. Comparação de médias de normas sociais do trabalho entre os quatro perfis de artesãos analisados

\begin{tabular}{llllllll}
\hline & Cluster 1 & Cluster 2 & Cluster 3 & Cluster 4 & Total & F & p \\
\hline Direitos & $6,7(0,5)$ & $6,3(0,7)$ & $6,4(0,7)$ & $6,5(0,7)$ & $6,4(0,7)$ & 2,1 &, 1 \\
Deveres & $6,1(0,8)$ & $5,7(0,9)$ & $5,8(0,9)$ & $6,1(1)$ & $5,8(0,9)$ & 1,6 &, 2 \\
\hline
\end{tabular}

Fonte: Dados da pesquisa.

As maiores médias de direitos e deveres podem ser observadas no primeiro cluster de artesãos, enquanto as menores dizem respeito ao segundo cluster. Ainda, identificamos que os clusters 01 e 04 apresentam as maiores médias para as normas sociais de direitos e deveres do trabalho. 0 contrário ocorreu para os clusters 02 e 03 que obtiveram as menores médias para ambas as normas sociais do trabalho, conforme observamos na Tabela 3. Portanto, artesãos reconhecidos (alto nível de visibilidade) aderem mais às normas sociais do trabalho que os artesãos não reconhecidos (baixo nível de visibilidade) sejam eles tradicionais ou de referência cultural.

Os resultados encontrados na amostra global, referente aos produtos valorizados do trabalho indicam a função do trabalho de manter o indivíduo ocupado, em atividade, como a função que obteve maior média $(17,86)$, sendo superior até mesmo à média obtida pela função econômica do trabalho (16,73), que nos estudos realizados pela equipe MOW (1987) representam o aspecto do trabalho mais valorizado pelos indivíduos. Conforme dados econômicos da atividade artesanal no Cariri cearense apresentados acima, observamos que a renda adquirida pelos artesãos é, na maioria dos casos, inferior a um salário mínimo. Talvez este seja um provável motivo que explique o fato de a função econômica da atividade artesanal não ser valorizada em primeiro lugar pelos artesãos.

Adicionalmente, acreditamos que a alta média alcançada pela função "manter o trabalhador ocupado" seja um reflexo da falta de outra opção de atividade de trabalho. Assim, algumas pessoas veem no artesanato a possibilidade de uma atividade que lhes permite estar engajado em uma tarefa, do contrário teriam uma parte do dia ociosa. Corroborando alguns discursos que transmitem a ideia de que o artesanato é uma ocupação, que graças à movimentação turística frequente na região lhes permite, de certa forma, dar vazão aos objetos produzidos.

Os produtos do trabalho que obtiveram as médias mais baixas se referem à função de status $(\mu=10,24 ; D P=8,03)$ e à função social do trabalho $(\mu=9,74 ; D P=6,03)$. Há indícios de que os artesãos investigados não considerem a atividade que realizam como importante para a sociedade, diferentemente da amostra de trabalhadores da indústria cultural examinada por Bendassolli e Borges-Andrade (2011), para a qual o fator utilidade social apresentou a segunda maior média entre os fatores avaliados (ética no trabalho, autonomia no trabalho, qualidade nas relações no trabalho, expressividade e identificação no trabalho) e a maior carga fatorial, corroborando o valor social da arte e da cultura, como crítica e como enriquecimento do espírito. 
Além da média geral da amostra para os sete fatores que compõem a dimensão denominada produtos valorizados do trabalho, a Tabela 6 também apresenta a média dos quatro grupos de artesãos analisados, para cada um destes fatores.

Tabela 6. Comparação de médias de resultados valorizados do trabalho entre os quatro perfis de artesãos analisados

\begin{tabular}{llllllll}
\hline & Cluster 1 & Cluster 2 & Cluster 3 & Cluster 4 & Total & F & p \\
\hline Status & $12,7(10,3)$ & $9,7(7,7)$ & $8,4(7,1)$ & $14(7,4)$ & $10,2(7,4)$ & 3,2 &, 02 \\
Rendimentos & $18,1(13,7)$ & $17,1(14,5)$ & $13,8(17,6)$ & $19,2(11,3)$ & $16,8(11,3)$ &, 81 &, 4 \\
Ocupado & $19,5(13,3)$ & $18,1(12,7)$ & $18,2(13,2)$ & $14,5(10,5)$ & $17,9(10,5)$ &, 61 &, 61 \\
Contatos & $12,6(7,5)$ & $15,7(8)$ & $14,7(9,8)$ & $15,1(7,2)$ & $15,1(7,2)$ &, 92 &, 4 \\
Sociedade & $8,8(5,6)$ & $9,7(5,5)$ & $10,3(7,7)$ & $10(5,6)$ & $9,8(5,6)$ &, 32 &, 81 \\
Interessante & $10,8(5)$ & $14,7(9,4)$ & $14,1(16,3)$ & $9,7(5,7)$ & $13,6(5,7)$ & 1,9 &, 13 \\
Autorealização & $15(10,4)$ & $14,8(11,8)$ & $20,5(22,9)$ & $19,4(20,2)$ & $16,5(20,2)$ & 1,6 &, 18 \\
\hline
\end{tabular}

Fonte: Dados da pesquisa.

Ainda assim, destacamos algumas diferenças de médias entre os quatro segmentos amostrais investigados. Por exemplo, a função de autorrealização representa a variável com média mais elevada para os artesãos de referência cultural reconhecidos $(\mu=19,4)$ e não reconhecidos $(\mu=20,5)$. Para os artesãos tradicionais reconhecidos e não reconhecidos, a função de autorrealização representa respectivamente a quarta e terceira posição entre os resultados esperados ou valorizados do trabalho.

Já a função de manter o trabalhador ocupado é a variável com média mais elevada para os grupos de artesãos tradicionais reconhecidos $(\mu=19,5)$ e não reconhecidos $(\mu=18,1)$. Quando analisamos a posição para os dois outros grupos, identificamos que para os artesãos de referência cultural não reconhecidos ela representa a segunda função do trabalho mais importante e para os artesãos de referência cultural reconhecidos, ela ocupa a quarta posição, ou seja, entre as variáveis que compõem a dimensão resultados esperados do trabalho, ela possui a quarta maior média. Desta forma, verificamos o destaque da função autorrealização para os artesãos inovadores com alta ou baixa visibilidade. Por outro lado, a função de manter o trabalhador ocupado se mostra central para os artesãos de uma forma geral, exceto para grupo de artesãos inovadores reconhecidos.

No tocante à função de status do trabalho, a média da amostra total de artesãos investigados é a segunda mais baixa. No entanto, quando observamos as diferenças entre médias dos grupos para esta variável, constatamos que os artesãos com alta visibilidade (artesãos tradicionais e de referência cultural reconhecidos) obtiveram médias mais elevadas que os artesãos com baixa visibilidade (artesãos tradicionais e de referência cultural não reconhecidos). Parece congruente que artesãos que obtém sucesso em comercializar seus objetos para além dos limites da região Nordeste do Brasil, atingindo visibilidade de níveis nacional e internacional, percebam no trabalho artesanal uma forma de alcançar status ou prestígio social, uma vez que são reconhecidos em um círculo bem mais amplo que o próprio município onde desenvolve a atividade artesanal. 
Ainda, quando comparamos as médias alcançadas pelos artesãos com os resultados obtidos por trabalhadores urbanos, observamos diferenças entre três variáveis que merecem destaque. Para os trabalhadores urbanos estudados por Bastos, Pinho e Costa (1995) a autorrealização apareceu como resultado mais valorizados pelos trabalhadores. Entre os artesãos, a autorrealização ocupa a terceira posição entre os resultados valorizados no trabalho e apresenta média quatro pontos menor que a obtida por trabalhadores urbanos. Finalmente, 0 resultado de manter o sujeito ativo foi o de maior média entre os artesãos (cinco pontos mais alta que a média de trabalhadores urbanos para a mesma variável). Assim, podemos vislumbrar algumas diferenças entre artesãos rurais e trabalhadores urbanos, no modo como significam o trabalho que realizam.

\section{CONSIDERAÇÕES FINAIS}

Os resultados apresentados até aqui permitem configurar a profissão de artesão como marcada por uma atribuição de alta centralidade do trabalho, uma vez que a avaliação da importância absoluta do trabalho obteve uma média muito próxima do escore máximo da escala utilizada. Quando avaliado juntamente com outras áreas da vida, o trabalho assume a segunda posição de maior importância e a família assume a primeira posição em ordem de importância. Diferente de outros estudos realizados sobre significado do trabalho, identificamos que para a amostra em questão a religião aparece em terceiro lugar de importância com média consideravelmente superior às esferas comunidade e lazer. Resultado que possivelmente reflete a alta religiosidade da comunidade local.

Quando lançamos o olhar para as diferenças entre as médias dos quatro perfis de artesãos analisados, observamos que os artesãos de referência cultural reconhecidos (altos escores de inovação e visibilidade) conferem maior importância ao trabalho que os outros três perfis avaliados. No entanto, quando a esfera da vida analisada é o lazer, constatamos que os artesãos tradicionais não-reconhecidos apresentam maior média para esta esfera da vida.

O conjunto dos resultados revela que, em relação às normas sociais, o trabalho exercido pelos artesãos da região do Cariri cearense se posiciona mais como um direito, que como um dever. Por sua vez, no que diz respeito aos motivos associados ao fato de trabalhar chamou a atenção algumas diferenças detectadas entre as médias dos artesãos pertencentes aos quatro clusters. Enquanto os artesãos considerados de alta inovação percebem no trabalho uma fonte de realização, como um caminho para se sentirem felizes, ou como uma maneira de alcançarem certo prestígio social perante seus pares e consumidores; para os artesãos tradicionais, o trabalho assume a função de mantê-los ocupados, o que constitui para estes artesãos uma opção melhor que a ociosidade.

A função de status do trabalho possui diferentes médias entre os clusters analisados. No entanto, percebemos que os artesãos reconhecidos (com altos escores em visibilidade) possuem maiores médias nesta variável, quando comparados aos artesãos não-reconhecidos (com baixos escores de visibilidade). Assim, temos indícios de que as motivações para o trabalho de artesãos variam em função do nível de inovação e do nível de visibilidade por eles alcançados.

Destacamos que embora se tratando de um grupo relativamente homogêneo de profissionais, que compartilham contexto histórico-geográfico e sociocultural, foi possível 
observar algumas distinções entre os quatro perfis artesanais analisados, que ressaltam peculiaridades de cada pequeno grupo. No tocante à quantidade de artesãos pertencentes a cada um dos perfis, apontamos como sugestão para pesquisas futuras, a necessidade de aumento da amostra investigada, a fim de fortalecer a confiabilidade das diferenças estatísticas encontradas.

De forma conclusiva, reiteramos a existência de esforços de investigação que se debruçam sobre contextos de trabalho diferentes dos tradicionalmente abordados em POT, sobretudo contextos relacionados à arte e cultura (Bendassolli \& Borges-Andrade, 2011; 2015a; Bendassolli \& Coelho-Lima, 2015, Bastos \& Aguiar, 2015). Assim, tal artigo se apresenta como uma contribuição para a ampliação do entendimento deste contexto do trabalho e para o acúmulo de conhecimento que venha a contribuir para consolidar uma linha de estudo que se dedique a investigar trabalhadores da economia cultural.

\section{REFERÊNCIAS}

Aguiar, C. V. N. (2016). Interfaces entre o trabalho e a família e os vínculos organizacionais: Explorando a tríade família-trabalho-organização. Tese de Doutorado. Universidade Federal da Bahia, Bahia.

Araújo, I. M. (2006). Os Novos Espaços Produtivos: Relações sociais e vida econômica no Cariri cearense, 2006. Tese de Doutorado em Sociologia. Universidade Federal do Ceará, Fortaleza.

Bastos, A. V. B.; Aguiar, C. V. N. (2015). Centralidade do Trabalho e Conflito Trabalho-Família: comparando trabalhadores urbanos e rurais. In: Batos, A. C., Moreira, L., Petrini, G., Alcântra, M. (2015). Família no Brasil: recurso para a pessoa e para a sociedade. Curitiba: Editora Juruá.

Bastos, A. V. B.; Pinho, A. P. M.; Costa, C. A. (1995). Significado do trabalho: um estudo entre trabalhadores inseridos em organizações formais. Revista de Administração de Empresas, 35 (6), 20-29.

Bendassolli, P. F. (2009). Psicologia e trabalho. Apropriações e significados. São Paulo: Cengage Learning.

Bendassolli, P. F., Alves, J. S. C., \& Torres, C. C. (2014). Inventário sobre significado do trabalho de profissionais de indústrias criativas. Avaliação Psicológica, 13(2), 177-186.

Bendassolli, P. F. \& Borges-Andrade, J. E. (2015b). Escala do Trabalho com Sentimento (EST). In: Puente-Palacios, K.; Peixoto, A. L. A. (2015). Ferramentas de diagnóstico para organizações e trabalho. Um olhar a partir da psicologia. Porto Alegre: Artmed.

Bendassolli, P. F. \& Borges-Andrade, J. E. (2015a). Meaning, Meaningfulness, and Tensions in Artistic Work. Revista Psicologia: Organizações e Trabalho, 15(1): 71-81

Bendassolli, P. F. \& Borges-Andrade, J. E. (2011). Significado do trabalho nas indústrias criativas. Revista de Administração de Empresas [online], 51 (2): 143-159.

Borges, L. O. (1999). A estrutura factorial dos atributos valorativos e descritivos do trabalho: um estudo empírico de aperfeiçoamento e validação de um questionário. Estudos de Psicologia. Natal, 4 (1): 107-139. 
Borges, L. O. (1997). Os atributos e a medida do significado do trabalho. Psicologia: Teoria e Pesquisa, 13 (2), 211-221.

Borges, L. O., Barros, S. C. (2015). Inventário de significado do trabalho para trabalhadores de baixa instrução. Puente-Palacios, K., Peixoto, A. L. A. (2015). Ferramentas de diagnóstico para organizações e trabalho. Um olhar a partir da psicologia. Porto Alegre: Artmed.

Borges, L. de O.; Pinheiro, J. Q. (2002). Estratégias de coleta de dados com trabalhadores de baixa escolaridade. Estudos de Psicologia, 7(número especial): 53-63.

Borges, L. O.; Tamayo, A. (2001). A estrutura cognitiva do trabalho. Revista Psicologia Organização e Trabalho, 1 (2): 11-44.

Borges, L. O.; Tamayo, A.; Alves-Filho, A. (2005). A. Significado do trabalho entre os profissionais de saúde. In: Borges, L. O. (Org.). Os profissionais de saúde e seu trabalho. São Paulo: Casa do Psicólogo, p. 143-223.

Borges, L. O. \& Yamamoto, O. H. (2010). O significado do trabalho para psicólogos brasileiros. In: Bastos, A. V. B. \& Gondim, S. M. G. (Orgs). O trabalho do psicólogo no Brasil. Porto Alegre: Artmed.

Grangeiro, R. R. (2015). O trabalho do artesão do Cariri cearense: sua história, práticas e significados da atividade profissional. Tese de Doutorado. Universidade Federal da Bahia, Bahia.

Kubo, S. H., Gouvêa, M. A.; Mantovani, D. M. N. (2013). Dimensões do significado do trabalho e suas relações. Revista Pretexto, 14 (3), 28-28.

Meaning of Work International Research Team - MOW . (1987). The meaning of working. London: Academic Press.

Rodrigues, A. C. de A.; Bastos, A. V. B. (2012). Entrincheiramento organizacional: construção e validação da escala. Psicologia: Reflexão e Crítica, 25 (4), 688-700.

Rogelberg, S. G.; Church, A. H.; Waclawski, J.; Stanton, J. M. (2004). Organizational Survey Research. In: Rogelberg, S. G. (2004). Handbook of Research Methods in Industrial and Organizational Psychology. Blackwell Publishing. Blackwell Reference Online. 09 May 2014 https://www-blackwellreference-com.frodon.univparis5.fr/subscriber/tocnode.html?id=g9781405127004_chunk_g97814051270049

Soares, C. R. V. (1992). Significado do trabalho: um estudo comparativo de categorias ocupacionais. Dissertação de mestrado. Universidade de Brasília.

Tolfo, S. R. (2015). Significados e sentidos do trabalho. In: Bendassolli, P. F.; Borges Andrade, J. E. (2015). Dicionário de psicologia do trabalho e das organizações. São Paulo: Casa do psicólogo.

Vale, C. do; Silva Jr, J. T. (2012). Catálogo de artesanato caririense: Juazeiro do Norte, Crato, Barbalha e Caririaçu. Juazeiro do Norte: BSG - Bureau de Serviços Gráficos. (Série editorial LIEGS). 